\title{
CONHECIMENTO DE MULHERES QUE FAZEM SEXO COM MULHERES SOBRE O PAPILOMAVÍRUS HUMANO
}

\author{
Daniela Comelis Bertolin ${ }^{1}$, Rita de Cássia Helú M. Ribeiro², Claudia Bernardi Cesarino², Dayana Coelho da Silva ${ }^{3}$,
} Dilma de Oliveira Prado ${ }^{3}$, Eva Socorro Parro ${ }^{4}$

RESUMO: Estudo quantitativo e descritivo, que teve como objetivo verificar o conhecimento de mulheres que fazem sexo com mulheres sobre as formas de transmissão, prevenção e fatores de risco relacionados ao papiloma vírus humano (HPV). Foi realizado com 31 mulheres residentes no Município de São José do Rio Preto, Estado de São Paulo. Os dados foram coletados por meio de questionário estruturado com 17 questões, analisados com auxílio do programa estatístico Statistical Package of Social Sciences e estatística descritiva. Constatou-se que a média de idade das mulheres foi de 39,5 anos, e que 52\% possuíam entre 9 e 11 anos de estudo. Em relação ao conhecimento, 68\% das mulheres não sabiam o significado do HPV, $58 \%$ acreditavam que a camisinha protege totalmente, e $45 \%$ responderam que o Papanicolau deve ser realizado duas vezes ao ano. Concluiu-se que há vulnerabilidade para contaminação por HPV devido à exposição aos fatores de risco e falta de conhecimento.

PALAVRAS-CHAVE: Homossexualidade feminina; Doenças sexualmente transmissíveis; Homossexualidade; Conhecimento.

\section{KNOWLEDGE OF WOMEN WHO HAVE SEX WITH WOMEN ABOUT HUMAN PAPILLOMAVIRUS}

\begin{abstract}
A quantitative and descriptive study, aimed at verifying the knowledge of women who have sex with women on ways of transmission, prevention and risk factors regarding to human papillomavirus (HPV). It was conducted with 31 women living in the city of Sao Jose do Rio Preto, São Paulo. Data were collected through structured questionnaire with 17 questions analyzed with the aid of the Statistical Package of Social Sciences and descriptive statistics. It was found that the average age of women was 39.5 years, and that $52 \%$ had between 9 and 11 years of study. Regarding knowledge, $68 \%$ of women did not know the significance of HPV, $58 \%$ believed that condom protects fully $45 \%$ responded that Pap smears should be performed twice a year. It was concluded that there is a vulnerability to contamination due to exposure to HPV risk factors and lack of knowledge.
\end{abstract}

KEYWORDS: Female homosexuality; Sexually transmitted diseases; Homosexuality.

\section{CONOCIMIENTO DE MUJERES QUE HACEN SEXO CON MUJERES ACERCA DEL PAPILOMAVIRUS HUMANO}

RESUMEN: Estudio cuantitativo y descriptivo, que tuvo como objetivo verificar el conocimiento de mujeres que hacen sexo con mujeres acerca de las formas de transmisión, prevención y factores de riesgo del papiloma virus hunano (HPV). Fue realizado con 31 mujeres residentes en municipio de São José do Rio Preto, estado de São Paulo. Los datos fueron recogidos por medio de cuestionario estructurado con 17 cuestiones, analizados con auxilio del programa estadístico Statístical Package of Social Sciences y estadística descriptiva. Se ha constatado que la media de edad de las mujeres fue de 39,5 años, y 52\% poseían entre 9 y 11 años de estudio. En relación al conocimiento, 68\% de las mujeres no sabían el significado del HPV, $58 \%$ creían que el condón protege totalmente, $45 \%$ contestaron que el Papanicolau debe ser realizado dos veces al año. La conclusión es que hay vulnerabilidad para contaminación por HPV a causa de la exposición a los factores de riesgo y falta de conocimiento.

PALABRAS CLAVE: Homosexualidad femenina; Enfermedades sexualmente transmisibles; Homosexualidad.

\footnotetext{
${ }^{1}$ Enfermeira. Mestre em Enfermagem. Docente da Universidade Paulista-UNIP.

${ }^{2}$ Enfermeira. Doutor em Enfermagem. Docente da Faculdade de Medicina de São José do Rio Preto-FAMERP.

${ }^{3}$ Acadêmica do Curso de Enfermagem da UNIP.

${ }^{4}$ Enfermeira. Especialista em Enfermagem em Unidade de Terapia Intensiva. Docente da UNIP.
}

\author{
Autor correspondente: \\ Daniela Comelis Bertolin \\ Universidade Paulista \\ R. Guatemala, 190 - 15020-240 - São José do Rio Preto-SP-Brasil \\ E-mail: danicomelis@bol.com.br
}

Recebido: 06/12/09 Aprovado: 02/07/10 


\section{INTRODUÇÃO}

Estima-se que de $75 \%$ a $80 \%$ da população sexualmente ativa será infectada pelo Papilomavírus humano (HPV) durante sua vida; este é transmitido por contato sexual e apresenta elevada prevalência em ambos os sexos ${ }^{(1)}$. As infecções por HPV começaram a chamar a atenção quando houve correlação entre as lesões virais e o câncer do colo do útero. Este tipo de câncer é o segundo mais comum entre mulheres em todo o mundo, com elevada prevalência em países em desenvolvimento ${ }^{(2)}$.

No Brasil, o câncer do colo do útero é o segundo mais incidente, na maioria das regiões, sendo superado apenas pelos tumores de pele não-melanoma. A maioria dos casos é encontrada em estágios avançados e a estimativa média de sobrevida é de $49 \%$ em cinco $\operatorname{anos}^{(3)}$.

Até o momento, mais de 100 tipos de HPV são conhecidos; destes, 20 podem infectar o trato genital e todos são considerados potenciais carcinógenos; entretanto, dois tipos são responsáveis por $60 \%$ dos casos de câncer do colo do útero, os vírus 16 e $18^{(4-5)}$.

Quando associados a outros fatores de risco, os tipos de vírus 16 e 18, com alto risco oncogênico, têm relação com o desenvolvimento das neoplasias intraepiteliais e do câncer invasor do colo do útero. Outros fatores de risco podem ser: alta paridade, uso prolongado de contraceptivos orais, início precoce da atividade sexual e tabagismo ${ }^{(5-6)}$.

A transmissão do HPV pode ocorrer por meio do contato direto com o epitélio vaginal, oral ou anal. O grau de contágio é relativamente alto, com $25 \%$ a $65 \%$ dos indivíduos contaminados após relação sexual com parceiros infectados, e as lesões podem ser facilmente disseminadas pelo processo de autoinoculação para regiões circunvizinhas, possibilitando o acesso direto das partículas virais às camadas mais profundas por meio de microtraumatismo no epitélio ${ }^{(7)}$.

As células afetadas constituem um reservatório viral e o período de incubação varia de 1 a 8 meses, mas, na maioria dos casos, a infecção permanece latente, podendo ter um curso bastante variado, progredindo de lesão subclínica a clínica no mesmo indivíduo. A evolução da lesão está relacionada com a competência imunológica do hospedeiro em eliminar ou manter a expressão viral ${ }^{(8)}$.

A prevenção do câncer do colo do útero é de grande importância na área da Saúde da Mulher, podendo ser desenvolvidas ações de prevenção que permitem a redução da mortalidade por esse tipo de câncer ${ }^{(9)}$.

Quanto à homossexualidade feminina e sua relação com a saúde, do ponto de vista da saúde pública, deve-se ter uma maior preocupação se comparada à homossexualidade masculina. Autores atentam para a existência de vários fatores associados a diferentes problemas de saúde nesta população, tais como câncer de mama e colo do útero, menor utilização de serviços de saúde, uso abusivo de álcool e drogas ilícitas, tabagismo e níveis elevados de sofrimento psíquico ${ }^{(10)}$.

Entretanto, há dois desafios a serem enfrentados nos estudos dos fatores associados às questões de saúde deste grupo populacional: o primeiro se refere às dificuldades de operacionalização e definição de conceitos com vistas à sua identificação; e o segundo diz respeito à variação das parcerias sexuais e do seu padrão de ocorrência ao longo da vida. Uma mulher pode ter relações com outras mulheres de forma eventual ou regular, variando esse padrão ao longo do tempo. Pode ainda ter relações com parceiras de comportamento exclusivamente homossexual ou parceiras que tenham relações com homens, de forma esporádica ou regular. Essa mesma mulher pode, ela própria, ter relações com homens, de forma esporádica ou regular ${ }^{(10)}$.

Considera-se que a disjunção entre desejos, práticas e identidades, abundantemente registrada na literatura sobre sexualidade, e o entrecruzamento entre gênero, sexualidade e outros marcadores sociais de diferença (como raça, classe e geração) demandam atenção para a diversidade interna da população constituída por essa categoria ${ }^{(11)}$.

Ao mesmo tempo, fica evidente o quadro de escasso conhecimento existente no Brasil relativo às necessidades de saúde dessa população; o conhecimento sobre o seu acesso aos serviços de saúde, em especial aqueles voltados para saúde sexual e reprodutiva, é uma dimensão fundamental para a formulação de políticas de saúde adequadas ${ }^{(10)}$.

As questões referentes à saúde sexual desta parcela da população são preocupantes pela existência de poucas informações disponíveis sobre este assunto no Brasil, e por haver maior vulnerabilidade entre mulheres que fazem sexo com mulheres devido por conta da menor frequência de realização de exames preventivos, menos solicitação de exames pelos profissionais da área da saúde, e por essas mulheres nem sempre realizarem os tratamentos, ou realizarem apenas quando surgem complicações com maiores agravos à sua saúde ${ }^{(12)}$.

Além disso, a menor procura dos serviços 
de saúde pode estar relacionada à discriminação ou despreparo dos profissionais para atendê-las, negação do risco pelas mesmas e dificuldades em assumir a sexualidade. A consulta ginecológica é, para a paciente e para o profissional, um momento delicado. A comunicação é muito importante para fortalecer a relação interpessoal, de forma que essas mulheres fiquem à vontade para falar abertamente sobre sua orientação sexual e expor suas inquietações, pois para a maioria delas é um momento de exposição da intimidade física e comportamental ${ }^{(11)}$.

Portanto, são necessárias atividades de educação em saúde capazes de oferecer informações sobre os fatores de risco para a infecção por HPV, de forma que influenciem na adesão da cliente ao diagnóstico e tratamento ${ }^{(13)}$. Neste contexto, este estudo teve por objetivo verificar o conhecimento de mulheres que fazem sexo com mulheres sobre as formas de transmissão, prevenção e fatores de risco para adquirir o HPV.

\section{METODOLOGIA}

Foi realizado um estudo descritivo e quantitativo com mulheres que fazem sexo com mulheres, contatadas por meio do Centro Municipal de Prevenção e Diagnóstico DST/Aids, local escolhido por atender um público específico de homossexuais, bissexuais, travestis, transexuais, profissionais do sexo e usuários de drogas injetáveis. Neste local, os profissionais são preparados para tratar com público, de forma que o deixe à vontade para falar abertamente sobre sua orientação sexual. A equipe é composta por psicóloga, enfermeira, técnica em enfermagem, assistente social e profissionais administrativos.

A amostra estudada foi constituída com os seguintes critérios de inclusão: mulher que admite praticar sexo com mulheres; adulta (18 anos ou mais); e com condições de responder ao questionário sem prejuízo das respostas por motivos de deficiência auditiva ou comportamento coerente com doenças psiquiátricas. No que diz respeito à definição conceitual da população, a escolha da categoria "mulheres que fazem sexo com mulheres" evita possíveis problemas que abranjam comportamento e identidades sexuais, como descritos em outros estudos ${ }^{(10-11)}$.

O instrumento de coleta de dados incluiu 17 questões estruturadas, elaborado para este estudo, embasado no formulário do Ministério da Saúde para a notificação de DST/Aids, e desenvolvido com a finalidade de verificar o conhecimento das mulheres que fazem sexo com mulheres sobre o HPV. Foi realizado um estudo-piloto com 8 mulheres, e foram feitas adaptações para melhor compreensão das perguntas pelas entrevistadas. As entrevistas do estudo-piloto não foram incluídas na pesquisa para não prejudicar o padrão de respostas, já que o questionário recebeu adaptações.

A população estudada foi recrutada após contato telefônico pelos profissionais do Centro Municipal de Prevenção e Diagnóstico DST/Aids e agendamento da entrevista no domicílio, em horário estabelecido pelas próprias mulheres. A coleta de dados realizada no domicílio promoveu maior comodidade e confidencialidade para as mulheres. Nas entrevistas, as pesquisadoras explicaram sobre os procedimentos da pesquisa. A coleta de dados ocorreu durante o mês de outubro de 2008 , e foi iniciada após a aprovação pelo parecer consubstanciado n. 91/08 do Comitê de Ética e Pesquisa local. As mulheres foram informadas dos procedimentos da pesquisa e assinaram o Termo de Consentimento Livre e Esclarecido.

Para a análise dos dados foi elaborada uma planilha no progama Microsoft Excel 2000, que foi transferida para o programa estatístico Statistical Package of Social Sciences (SPSS, 1999) versão 11.5, após dupla digitação, por meio do qual foi feita a análise dos dados utilizando a estatística descritiva, com frequência absoluta e percentual.

\section{RESULTADOS E DISCUSSÃO}

A população estudada foi constituída de 31 mulheres que fazem sexo com mulheres, sendo que 23 (74\%) mulheres faziam sexo somente com mulheres e $8(26 \%)$ com homens e mulheres. A idade variou entre 18 e 61 anos, com média de 39,5 anos. Em outro estudo com mulheres que fazem sexo com mulheres, a idade variou entre 17 e 59 anos, com média de 33,5 $\operatorname{anos}^{(14)}$.

Quanto à escolaridade, 16 (52\%) mulheres tinham entre 9 e 11 anos de estudo, 12 (39\%) tinham entre um e 8 anos de estudo, 2 (6\%) tinham 12 anos ou mais de estudo, e 1 (3\%) era analfabeta. Em pesquisa realizada na Município do Rio de Janeiro, a escolaridade de $46,4 \%$ das mulheres que faziam sexo com mulheres era de 11 anos ou mais de estudo ${ }^{(15)}$.

A tabela 1 ilustra os fatores de risco para adquirir o HPV, referidos pelas mulheres neste estudo. 
Tabela 1 - Fatores de risco para contaminação por HPV. São José do Rio Preto, 2008

\begin{tabular}{|c|c|c|}
\hline Variáveis & $\mathbf{n}$ & $\%$ \\
\hline \multicolumn{3}{|c|}{ Ingestão de bebida alcoólica } \\
\hline Nunca & 2 & 7 \\
\hline Raramente & 15 & 48 \\
\hline Semanalmente & 10 & 32 \\
\hline Diariamente & 4 & 13 \\
\hline \multicolumn{3}{|l|}{ Tabagismo } \\
\hline Não fuma & 12 & 39 \\
\hline Às vezes & 3 & 10 \\
\hline Fumantes & 16 & 51 \\
\hline \multicolumn{3}{|c|}{ Idade da primeira relação sexual } \\
\hline$<10$ & 3 & 10 \\
\hline $10 \vdash 16$ & 10 & 32 \\
\hline $16 \vdash 21$ & 16 & 52 \\
\hline $21-26$ & 1 & 3 \\
\hline $26+30$ & 1 & 3 \\
\hline \multicolumn{3}{|l|}{ Possui parceria fixa } \\
\hline Sim & 26 & 84 \\
\hline Não & 5 & 16 \\
\hline \multicolumn{3}{|c|}{$\begin{array}{l}\text { Uso de barreira nas relações sexuais } \\
\text { com mulheres }\end{array}$} \\
\hline Sempre & 2 & 7 \\
\hline Poucas vezes & 5 & 16 \\
\hline Nunca & 24 & 77 \\
\hline \multicolumn{3}{|c|}{$\begin{array}{l}\text { Uso de preservativo nas } \\
\text { relações sexuais com homens }\end{array}$} \\
\hline Sempre & 6 & 75 \\
\hline Na maioria das vezes & 1 & 12,5 \\
\hline Poucas vezes & 1 & 12,5 \\
\hline
\end{tabular}

Entre as mulheres entrevistadas, 15 (48\%) referiram raramente ingerir bebida alcoólica e 16 (51\%) eram fumantes. Em relação à primeira relação sexual, para $16(52 \%)$ mulheres ela aconteceu entre 16 e 20 anos; $42 \%$ das mulheres tiveram a primeira relação sexual com idade igual ou inferior a 15 anos; e $17(55 \%)$ mulheres tiveram sua primeira relação sexual com homens. Em estudo sobre infecção por HPV em mulheres heterossexuais, a primeira relação sexual foi, em média, aos 18 anos, e 20\% das mulheres tiveram a primeira relação sexual com idade igual ou menor a $15 \operatorname{anos}^{(16)}$.

Das mulheres entrevistadas, $26(84 \%)$ referem parceria fixa, sendo 25 (96\%) com mulher e 1 (4\%) com homem. Em outro estudo, o percentual de parceria fixa foi de $43 \%$ das mulheres que fazem sexo com mulheres ${ }^{(15)}$. Quanto ao uso de barreira nas relações sexuais com mulheres, 24 (77\%) mulheres referiram nunca usar. Sobre o uso de barreira nas relações sexuais com homens, $6(75 \%)$ mulheres usam o preservativo sempre; vale ressaltar que apenas $8 \mathrm{mu}$ lheres referiram fazer sexo com homens e mulheres. Em estudo realizado com mulheres heterossexuais, no Estado do Rio Grande do Sul, 29\% referiram uso de preservativos na relação sexual ${ }^{(17)}$.

Os fatores de risco para adquirir o HPV e também para o desenvolvimento do câncer do colo do útero incluem fatores sociais, ambientais e hábitos de vida, início da atividade sexual antes dos 18 anos e tabagismo. As mulheres podem reduzir os fatores de risco usando o método de barreira nas relações sexuais ${ }^{(18)}$.

A tabela 2 ilustra o conhecimento das mulheres deste estudo sobre a transmissão e prevenção do HPV.

Tabela 2 - Conhecimento sobre transmissão e prevenção do HPV. São José Rio Preto, 2008

\begin{tabular}{lcc}
\hline Variáveis & n & \% \\
\hline Sabe o que significa HPV & 10 & 32 \\
Sim & 21 & 68 \\
Não & & \\
Em quais locais do corpo é encontrado & & \\
o HPV & 5 & 16 \\
Pênis e vagina & 9 & 29 \\
Pênis, vagina e ânus & 17 & 55 \\
Pênis, vagina, ânus, laringe, esôfago e pele & & \\
O uso da camisinha protege contra o HPV & & \\
Totalmente & 18 & 58 \\
Parcialmente & 11 & 36 \\
Não protege & 2 & 6 \\
Frequência que deve realizar o & & \\
Exame de Papanicolau & & \\
2 vezes ao ano & 14 & 45 \\
1 vez ao ano, ou após dois resultados & 10 & 32 \\
negativos após 3 anos. & & \\
1 vez a cada 2 anos & 3 & 10 \\
Quando notar alguma alteração & 3 & 10 \\
Quando se tem relação sexual com homens & 1 & 3 \\
\hline
\end{tabular}

Entre as respondentes, $21(68 \%)$ mulheres responderam que não sabiam o que significava HPV, e $17(55 \%)$ mulheres responderam corretamente, que acreditavam que o HPV poderia ser encontrado na 
vagina, pênis, ânus, laringe, esôfago e pele.

Quanto ao uso da camisinha, 18 (58\%) mulheres acreditavam que ela protege totalmente, indicando falta de conhecimento sobre o assunto, pois o correto seria responder "parcialmente".

Com relação à frequência da realização do exame do Papanicolaou, 14 (45\%) mulheres responderam errado, que deveria ser realizado duas vezes ao ano. Em estudo realizado em São Paulo, 8\% dos exames de Papanicolaou tiveram o diagnóstico anormal e em $6 \%$ dos exames foi diagnosticado $\mathrm{HPV}^{(19)}$.

Das 31 mulheres, 14 (45\%) mulheres tinham realizado o exame de Papanicolaou há menos de um ano, 7 (23\%) mulheres nunca realizaram, 6 (19\%) tinham realizado o exame há um ano, 3 (10\%) tinham realizado o exame há dois anos e uma mulher tinha realizado o exame há mais de três anos. Em outros estudos com mulheres que fazem sexo com mulheres e com mulheres heterossexuais, o percentual de mulheres que referiram nunca ter realizado o exame de Papanicolaou foi menor que $18 \%$. A falta de conhecimento adequado sobre o exame de Papanicolaou e a importância da realização deste pelas mulheres constitui um barreira de grande importância para os serviços de saúde, pois limita o acesso ao rastreamento do câncer de colo do útero ${ }^{(19-21)}$.

Em relação à consulta ginecológica, 10 (32\%) mulheres referiram que nunca falavam sobre sua orientação sexual com o médico; 8 (26\%) mulheres referiram ficar à vontade para falar sobre sua orientação sexual; 7 (23\%) mulheres referiram sentir-se constrangidas, mas falavam sobre sua orientação sexual e $6(20 \%)$ mulheres referiram nunca ter ido ao ginecologista. Em uma pesquisa com mulheres que fazem sexo com mulheres, $60 \%$ das mulheres relataram sua orientação sexual ao ginecologista e $3 \%$ referiram nunca ter ido ao mesmo ${ }^{(14)}$.

A justificativa para não fazer acompanhamento ginecológico pode ser a não-identificação de necessidade, havendo uma associação, para essas mulheres, da consulta ginecológica apenas com questões ligadas ao sexo com homens, reprodução e $\mathrm{DST}^{(11)}$.

\section{CONCLUSÃo}

Os dados sociodemográficos da população estudada são semelhantes aos de outras populações de estudos encontrados, com idade média acima de 30 anos, e escolaridade geral de ensino médio completo a ensino superior.
Há vulnerabilidade para a contaminação por HPV na população estudada devido à presença dos fatores de risco, tais como: idade precoce da primeira relação sexual, tabagismo, etilismo e, principalmente, a ausência de barreiras físicas nas relações sexuais com mulheres. Com relação aos fatores de risco, deve ser considerada a inexistência de barreiras de proteção que sejam práticas e populares para o sexo entre mulheres, sendo usado o plástico filme e outras alternativas.

Em relação ao conhecimento sobre as formas de prevenção e transmissão do HPV, foi constatado desconhecimento sobre o significado do HPV, e quase metade das mulheres do estudo não sabia onde o vírus pode ser encontrado.

Quanto à realização do exame Papanicolaou, a maioria das mulheres não sabia quando se deve realizá-lo; entretanto, quase metade delas havia realizado o exame há menos de um ano; mas $23 \%$ nunca o realizaram, sendo este um dado muito preocupante, pois estas mulheres podem ter o HPV ou outras infecções sexualmente transmissíveis e não saberem.

Deve ser considerada relevante a porcentagem de mulheres que referiram nunca falar sobre sua orientação sexual com o médico, bem como a das que referiram nunca ter ido ao ginecologista, porque isso pode indicar carência de acolhimento e encaminhamento desta população especial de mulheres pelo serviço de saúde e além da falta de esclarecimento sobre a necessidade de realizar exames preventivos.

Este estudo fornece informações para o planejamento de ações educativas para este grupo especial de mulheres quanto às formas de prevenção e transmissão do HPV e câncer do colo do útero, além de dados para a melhoria do acolhimento desta população nos serviços de saúde.

\section{REFERÊNCIAS}

1. Nadal SR, ManzioneCR. Vacinas contra opapilomavirus. Rev Bras Coloproctol.2006;26(3):337-40.

2. Tulio S. Relação entre a carga viral de HPV oncogênico determinada pelo método de captura híbrida e o diagnóstico citológico de lesões de alto grau. J Bras Patol Med Lab. 2007;43(1):31-5.

3. Ministério da Saúde (BR). Instituto Nacional de Câncer-INCA. Estimativa de câncer para 2008. [acesso em 10 out 2008]. Disponível: http://tiny.cc/rm58g 
4. Derchain SFM, Sarian LOZ. Vacinas profiláticas para o HPV. Rev Bras Ginecol Obstetrícia.2007;29(6):20-9.

5. Ministério da Saúde (BR). Manual de bolso: controle das doenças sexualmente transmissíveis DST. $2^{\mathrm{a}}$ ed. Brasília: Ministério da Saúde, 2006.

6. Rama CH. Prevalência do HPV em mulheres rastreadas para o câncer cervical. Rev Saúde Pública. 2008;42(1):45-63.

7. Silva EDC. Papiloma vírus humano. Rev Bras Anal Clín. 2004;36(3):137-42.

8. Filippin C. HPV - Relato de um caso clínico. Revista Rev Bras Anal Clín. 2003;35(2):97-9.

9. Madureira AB, Lunardi VL. A saúde como direito: o exame preventivo de câncer de colo uterino sobre o olhar da faltosa. Texto \& Contexto Enferm.2003;12(3):411-2.

10. Barbosa RM, Koyama MAH. Mulheres que fazem sexo com mulheres: algumas estimativas para o Brasil. Cad Saúde Pública. 2006;22(7):1511-4.

11. Fachinni R, Barbosa RM. Dossiê saúde das mulheres lésbicas: promoção da equidade e da integralidade. Rede Nacional Feminista de Saúde. 2006.

12. Fachinni R, Barbosa RM. Acesso a cuidados relativos à saúde sexual de mulheres que fazem sexo com mulheres em São Paulo/Brasil. Cad Saúde Pública. 2009;25(Suppl 2):S291-300.

13. Queiroz D. Infecção pelo papiloma vírus humano (HPV): incertezas e desafios. Acta Paul Enferm.2005;18(2):190-6.

14. Coelho LM. A representação social da homossexualidade feminina nos ginecologistas do ponto de vista das mulheres lésbicas e bissexuais. Rev Tesseract. 2001; 4:50-9.

15. Carrara S, Ramos S. Política, direito, violência e homossexualidade. $9^{\text {a }}$ ed. Rio de Janeiro: CEPESC; 2005.

16. Martins CMR. Associação entre idade ao início da atividade sexual subsequente infecção por papilomavírus humano: resultados de um programa de rastreamento brasileiro. Rev Bras Ginecol Obstetr. 2007;29(11):45-5.

17. Carreno I, Costa JSD. Uso de preservativos nas relações sexuais: estudo de base populacional. Rev
Saúde Pública. 2006;40(4):720-6.

18. Hass P. Vantagens da citologia de monocamada em preventivos de câncer de colo de útero. Rev Bras Anal Clín. 2003;35(3):143-6.

19. Pinto VM. Aspectos epidemiológicos das doenças sexualmente transmissíveis em mulheres que fazem sexo com mulheres [dissertação]. São Paulo(SP): Universidade de São Paulo; 2004.

20. Pinho AA. Fatores associados à realização do teste de Papanicolau entre mulheres em idade reprodutiva no município de São Paulo[dissertação]. São Paulo(SP): Universidade de São Paulo; 2002.

21. Oliveira LS, Almeida ACH. A percepção das mulheres frente ao exame de Papanicolaou: da observação ao entendimento. Cogitare Enferm. 2009;14(3):518-26. 